\title{
Do We Need to Wake Up to the Sleep Apnea Problem?
}

\author{
Neil S. Cherniack \\ New Jersey Medical School, Newark, N.J., USA
}

This issue of Respiration contains a survey by Zamarrón et al. [1] on the prevalence of sleep apnea in elderly people. The study confirms widely held ideas that sleep disturbances and symptoms related to poor sleep as well as sleep apnea are common in elderly people and suggests that sleep disturbances in the elderly are virtually epidemic [2-4].

Sleep apnea appears to be a quite serious health problem, but before we become unduly alarmed, we need more information. First, we need to better identify the consequences of sleep disturbances. That sleepiness can be embarrassing and lead to accidents is clear, but does it predispose to other health problems like hypertension? The significance of sleep-disordered breathing is controversial. We do not know for sure how many people who are classified as having sleep-disordered breathing according to the criteria used by Zamarrón et al. [1] go on to develop the full-fledged sleep apnea syndrome. Who should be treated is another question that requires better data. While nasal continuous positive airway pressure seems to be a quite effective way of reducing apneas during sleep, its cost-effectiveness remains to be established. There may be simpler ways of accomplishing the same objective. We have fairly good ideas on how sleep apnea can be prevented and the role of alcohol and obesity in predisposing to sleep apnea.
Sleep studies are an expensive and lengthy way to diagnose the sleep apnea syndrome. Most important, we need to develop better diagnostic techniques before we can accurately assess the prevalence and health effect of sleep apnea.

There are lots of questions about sleep apnea that need to be answered. Fortunately, increasingly better designed clinical research studies are gathering the data we need to develop evidence-based approaches to the detection and treatment of sleep apnea.

\begin{tabular}{ll}
\hline KARGER & ( ) 1999 S. Karger AG, Basel \\
Fax +4161306 1234 & 0025-7931/99/0664-0311\$17.50/0 \\
$\begin{array}{l}\text { E-Mail karger@karger.ch } \\
\text { www.karger.com }\end{array}$ & $\begin{array}{l}\text { Accessible online at: } \\
\text { http://BioMedNet.com/karger }\end{array}$
\end{tabular}

Neil S. Cherniack, MD Office of the Dean

UMDNJ - New Jersey Medical School

185 South Orange Avenue, Newark, NJ 07103-2714 (USA)

Tel. +1 973972 7937, Fax +1 9739727104 